\title{
Early-Age Tensile Basic Creep Behavioral Characteristics of High-Strength Concrete Containing Admixtures
}

\author{
Tongyuan $\mathrm{Ni} \mathbb{D}^{\mathbb{1 , 2 , 3}}$ Yang Yang $\mathbb{D}^{2,3}$ Chunping Gu $\mathbb{D}^{2,3}{ }^{2,3}$ Jintao Liu, ${ }^{2,3}$ Jin Chen, ${ }^{2}$ \\ and Xiaotian Lou $^{2}$ \\ ${ }^{1}$ College of Materials Science \& Engineering, Zhejiang University of Technology, Hangzhou 310014, China \\ ${ }^{2}$ College of Civil Engineering \& Architecture, Zhejiang University of Technology, Hangzhou 310023, China \\ ${ }^{3}$ Key Laboratory of Civil Engineering Structures \& Disaster Prevention and Mitigation Technology of Zhejiang Province, \\ Hangzhou 310023, China
}

Correspondence should be addressed to Yang Yang; yangyang@zjut.edu.cn

Received 7 January 2019; Accepted 7 April 2019; Published 8 May 2019

Academic Editor: Abdul Aziz bin Abdul Samad

Copyright (c) 2019 Tongyuan Ni et al. This is an open access article distributed under the Creative Commons Attribution License, which permits unrestricted use, distribution, and reproduction in any medium, provided the original work is properly cited.

\begin{abstract}
Tensile creep is an important parameter to evaluate cracking probability of high-strength concrete (HSC) structure, and the mineral admixtures have great effect on it. In this paper, the early-age tensile basic creep behaviors of HSC containing fly ash (FA) and blast furnace slag (BS) were investigated by experiments, and the influences of loading age and stress level (stress-strength ratio of initial loading) were evaluated. The results showed that FA promoted the early-age tensile basic creep while BS inhibited the early-age tensile creep. Moreover, the influence of loading age on early-age tensile basic creep of HSC was more significant, and the affected ages' duration was longer than that of plain concrete. The early-age tensile basic creep of HSC containing admixtures also showed linear creep characteristic after a certain age as HSC without admixtures, and the linear characteristic was more obvious at a later loading age. The tensile basic creep velocity of HSC containing FA was the highest, while HSC containing BS exhibited the lowest velocity. The influence of admixtures on velocities of tensile basic creep was gradually attenuated with the age growth in holding period.
\end{abstract}

\section{Introduction}

Creep plays an important role on the cracking resistance of concrete because it can relieve the stress and help to reduce the cracking potential of the concrete structure at the early age $[1,2]$. Therefore, concrete creep, especially tensile creep, is an important parameter to evaluate cracking probability of the concrete structure [3-7], and it is also one of the key characteristics that determine the internal stress development of constrained structures [8]. In the past few decades, related studies mainly focused on the compression creep behavior of mature concrete $[9,10]$. In recent years, more attention was paid to cracking behavior of high-strength concrete (HSC) at the early age; hence, the studies on the early-age creep of HSC have also been conducted [11-14]. In modern concrete, the admixtures were widely used to improve the concrete performance. The mineral admixtures had been widely used to ameliorate early cracking sensitivity of HSC [15-17]. Several researchers [17-23] investigated the tensile creep properties of HSC containing admixtures at the early age, but the research progress could not keep up with the pace of engineering applications. With the practical demand, it is urgent to reveal the tensile creep behaviors of HSC, especially the early-age tensile basic creep, so as to provide the basis for the stress analysis, cracking control, and engineering application of HSC at the early age.

Creep in concrete can be divided into two categories: basic creep and drying creep [12]. The tensile basic creep (following referred as tensile creep) is defined as creep without moisture exchange between concrete and the environment $[1,24-26]$. Figure 1 shows a schematic relation between basic creep, drying creep, and drying shrinkage.

The drying creep of sealed concrete could be ignored because the moisture has not exchanged with outside. So, the 


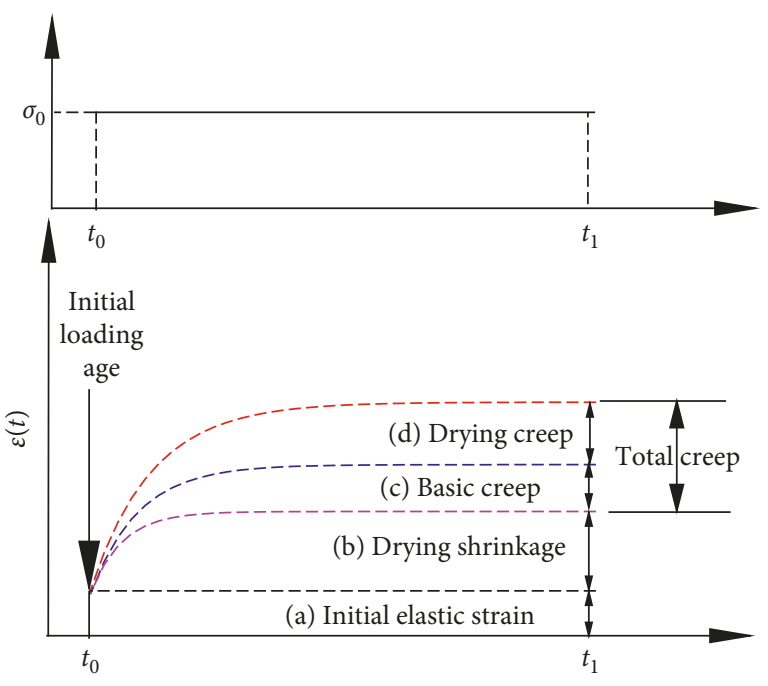

Figure 1: Sketch map of time-dependent strain of concrete under sustained loads.

total strain $\varepsilon_{\text {total }}$ of concrete under sustained loads is represented in Figure $2[1,2,25,26]$ and in the following equation:

$$
\varepsilon_{\text {total }}=\varepsilon_{\text {elastic }}+\varepsilon_{\mathrm{T}}+\varepsilon_{\mathrm{as}}+\varepsilon_{\text {tensile creep }}
$$

The instantaneous elastic strain $\varepsilon_{\text {elastic }}$ caused by the exerted tensile load can be measured in experiments; the temperature strain $\varepsilon_{\mathrm{T}}$ induced by temperature variation resulted from the hydration heated release, and the autogenous shrinkage $\varepsilon_{\text {as }}$ of the specimen can be measured by autogenous deformation experiments. So, the basic creep strain $\varepsilon_{\text {tensile creep }}$ can be calculated with the following equation:

$$
\varepsilon_{\text {tensile creep }}=\varepsilon_{\text {total }}-\varepsilon_{\text {elastic }}-\varepsilon_{\mathrm{T}}-\varepsilon_{\mathrm{as}} .
$$

According to Figure 2, the basic creep strain $\varepsilon_{\text {tensile creep }}$ can be calculated with the following equation:

$$
\varepsilon_{\text {tensile creep }}=\varepsilon_{\mathrm{B}}-\varepsilon_{\mathrm{A}}-\varepsilon_{\text {elastic }} \text {. }
$$

These three parameters in equation (3), i.e., $\varepsilon_{\mathrm{B}}\left(=\varepsilon_{\text {total }}\right)$, $\varepsilon_{\mathrm{A}}\left(=\varepsilon_{\mathrm{as}}+\varepsilon_{\mathrm{T}}\right)$, and $\varepsilon_{\text {elastic }}$, can be measured in experiments.

In addition, the creep compliance function $J\left(t, t_{0}\right)$ at age $t_{0}$ can be expressed with the following equation:

$$
J\left(t, t_{0}\right)=\frac{1}{\sigma}\left[\varepsilon_{\text {elastic }}\left(t_{0}\right)+\varepsilon_{\text {tensile creep }}\right]=\frac{1}{E_{\mathrm{c}}\left(t_{0}\right)}+C\left(t, t_{0}\right),
$$

where $C\left(t, t_{0}\right)$ denotes the specific creep, $\varepsilon_{\text {elastic }}\left(t_{0}\right)$ is the instantaneous elastic strain, $E_{\mathrm{c}}\left(t_{0}\right)$ is the elastic modulus of the specimen at age $t_{0}$, and $\sigma$ is the stress of the specimen under constant tensile load [1].

The early-age tensile creep of HSC is very hard to test. In order to test concrete tensile creep at early ages, temperatures of internal concrete at ages, imposed load, and autogenous shrinkage, a kind of test equipment was designed by Yang et al. [3, 27-30]. We had studied the tensile creep of concrete without admixture by using this device. This test equipment and method were also improved step by step in the test, and many research results were achieved [3, 27-30]. These studies indicated that the device could successfully measure the early-age tensile creep of concrete. Based on this observation, the research objective of this paper is to study the early-age tensile creep behaviors of HSC containing mineral admixtures by using this device. The influence of loading age, stress level, and mineral admixtures on earlyage tensile basic creep of HSC was tested and discussed.

\section{Experimental Programs}

\subsection{Raw Materials and Mixture Proportion}

2.1.1. Cement and Mixtures. Cement used in this study is PO 42.5 in accordance with Chinese GB 175-2007. Two kinds of admixtures were used in experiments: fly ash (FA) and blast furnace slag (BS). FA meets grade II ash standard in accordance with Chinese GB/T 1596-2017, and BS meets grade S95 standard in accordance with Chinese GB/T 203-2008. Tables 1 and 2 show the chemical composition and physical properties of cement and mineral admixtures.

2.1.2. Aggregate and Water Reducer. The crushed stone was used as the coarse aggregate, whose particle size was in the range of 5-31.5 $\mathrm{mm}$ in order to meet requirements of pump concrete in accordance with Chinese Standard JGJ/T 102011 (Technical Specification for Construction of Concrete Pumping). The apparent density of the crushed stone was $2700 \mathrm{~kg} / \mathrm{m}^{3}$. The fineness modulus of machine-made sand that used as fine aggregate was 2.40, and its apparent density was $2630 \mathrm{~kg} / \mathrm{m}^{3}$. Polycarboxylate superplasticizer (SP) provided by Zhejiang Huawei Building Materials Group Co. Ltd was used as the high-efficiency water reducing agent in this study.

2.1.3. Mix Proportion of Concrete. The mix proportion of HSC (strength grade of C50) in this paper is shown in Table 3. The slump flow of concrete mixture was controlled at $530+30 \mathrm{~mm}$, which was in accordance with Chinese Standard JGJ/T 10-2011 (Technical Specification for Construction of Concrete Pumping).

\subsection{Tensile Creep Test}

2.2.1. Specimen Preparation and Environmental Conditions of the Tensile Creep Test. The tests of tensile creep include two series of experiments, viz. the tensile creep test under constant load (Figure 3) and the autogenous shrinkage test without load (Figure 4). The size of tensile creep specimens and autogenous deformation specimens was $100 \mathrm{~mm} \times 100 \mathrm{~mm} \times 400 \mathrm{~mm}$. The temperature of the concrete molds was controlled at $20 \pm 1^{\circ} \mathrm{C}$. When the concrete was placed into the mold, the specimens must be immediately covered with the plastic film to avoid moisture exchange with the outside and be placed in the laboratory with the environmental temperature of $20 \pm 1^{\circ} \mathrm{C}$. Thermocouples were embedded in the concrete specimens to monitor the 


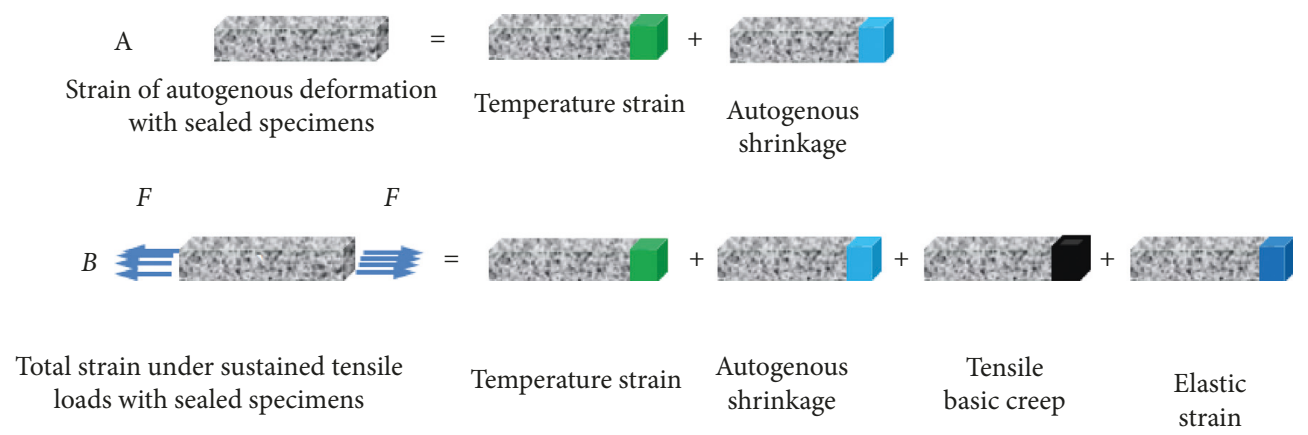

Figure 2: Tensile basic creep strain of sealed specimens can be divided from total strain.

TABle 1: Chemical composition of cement and mineral admixtures.

\begin{tabular}{lcccccrrr}
\hline Materials/index & $\mathrm{Al}_{2} \mathrm{O}_{3}$ & $\mathrm{SiO}_{2}$ & $\mathrm{CaO}$ & $\mathrm{Fe}_{2} \mathrm{O}_{3}$ & $\mathrm{MgO}$ & $\mathrm{K}_{2} \mathrm{O}$ & $\mathrm{Na}_{2} \mathrm{O}$ & $\mathrm{SO}_{3}$ \\
\hline Cement (C) & 6.99 & 24.95 & 54.33 & 2.83 & 2.16 & 0.66 & 0.21 & 2.89 \\
Fly ash (FA) & 41.4 & 46.6 & 3.18 & 3.90 & 0.22 & 0.72 & 0.00 & 0.61 \\
Blast furnace slag (BS) & 17.0 & 31.2 & 37.3 & 0.27 & 10.4 & 0.34 & 0.29 & 2.17 \\
\hline
\end{tabular}

TABle 2: Physical properties of cement and mineral admixtures.

\begin{tabular}{lcccc}
\hline Materials/index & Specific surface area $\left(\mathrm{m}^{2} / \mathrm{kg}\right)$ & Density $\left(\mathrm{g} / \mathrm{cm}^{3}\right)$ & Ignition loss $(\%)$ & Average grain size $(\mu \mathrm{m})$ \\
\hline Cement (C) & 368 & 2.99 & 3.66 & 26.04 \\
Fly ash (FA) & 337 & 2.03 & 4.79 & 62.12 \\
Blast furnace slag (BS) & 431 & 2.88 & 0.41 & 14.50 \\
\hline
\end{tabular}

TABLE 3: Concrete mixture proportions.

\begin{tabular}{lccc}
\hline \multirow{2}{*}{ Concrete composition $\left(\mathrm{kg} / \mathrm{m}^{3}\right)$} & \multicolumn{3}{c}{ Concrete mixtures } \\
& FA & BS & Trinary binder \\
\hline Cement & 391 & 279 & 307 \\
Fly ash & 167 & - & 112 \\
Blast furnace slag & - & 279 & 139 \\
Water & 167 & 167 & 167 \\
Coarse aggregate & 988 & 988 & 988 \\
Fine aggregate & 687 & 687 & 687 \\
$w / b$ & 0.3 & 0.3 & 0.3 \\
Superplasticizer $(\%)$ & 1.97 & 1.00 & 1.30 \\
Slump flow $(\mathrm{mm})$ & 550 & 540 & 550 \\
\hline
\end{tabular}

change of the internal temperature. The tensile creep specimens were demolded at the age of about $12 \mathrm{~h}$ and immediately sealed with plastic film and aluminum foil. Before the first $1 \mathrm{~h}$ of loading, a thin fast hard adhesive was coated on the central area of two sides of the specimen. After the adhesive being hardened, and polished, two $90 \mathrm{~mm}$ length strain gauges were attached to measure the total strain of the tensile creep specimen during the test.

2.2.2. Experimental Parameters. The loading age $(1 \mathrm{~d}, 2 \mathrm{~d}$, $3 \mathrm{~d}, 5 \mathrm{~d}$, and $7 \mathrm{~d}$ ), the level of stress (the ratio of initial loading stress/strength was $0.2,0.3$, and 0.4 ), and the admixtures type (with $30 \%$ fly ash, 50\% blast furnace slag, and $20 \%$ fly ash $+25 \%$ blast furnace slag) were taken as the experimental parameters.

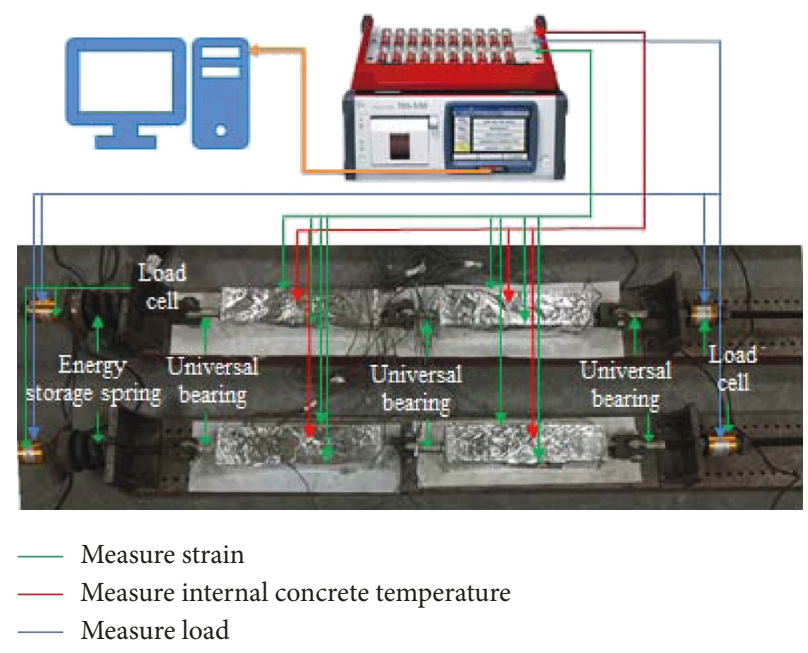

Figure 3: Tensile creep measurement system.

2.2.3. Tensile Creep Measurement Experiment. The tensile creep tests were performed using the test device developed by Yang et al. [23, 28-32]. The test device is shown in Figure 3. The device can realize axial and stable tensile loading and continuously measurement on stress, strain, and temperature during the test. All the data were automatically collected and recorded by the data acquisition instrument. The test data were recorded every 2 hours before the age of $7 \mathrm{~d}$ and every 6 hours after $7 \mathrm{~d}$. In order to improve the precision and consistency of the tensile loading, two load sensors were set: one was seated outside of the energy storage 


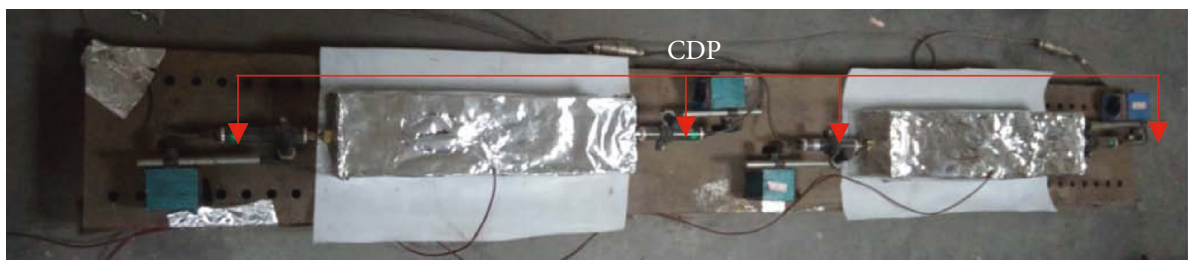

FIgURE 4: Physical map of autogenous deformation test.

TABLE 4: Experimental results of mechanical property related to tensile creep.

\begin{tabular}{|c|c|c|c|c|c|c|c|}
\hline \multirow[b]{2}{*}{ Material } & \multirow[b]{2}{*}{$\begin{array}{l}\text { Loading } \\
\text { age }(\mathrm{d})\end{array}$} & \multicolumn{3}{|c|}{ Applied load (kN) } & \multirow[b]{2}{*}{$\begin{array}{l}\text { Splitting tensile } \\
\text { strength }(\mathrm{MPa})\end{array}$} & \multirow[b]{2}{*}{$\begin{array}{l}\text { Compression } \\
\text { strength (MPa) }\end{array}$} & \multirow[b]{2}{*}{$\begin{array}{l}\text { Tensile modulus of } \\
\text { elasticity }(\mathrm{GPa})\end{array}$} \\
\hline & & $\begin{array}{l}\text { Stress/strength } \\
\text { ratio, } 0.2\end{array}$ & $\begin{array}{l}\text { Stress/strength } \\
\text { ratio, } 0.3\end{array}$ & $\begin{array}{l}\text { Stress/strength } \\
\text { ratio, } 0.4\end{array}$ & & & \\
\hline \multirow{5}{*}{ BS } & 1 & 5.81 & 8.72 & 11.62 & 1.85 & 14.84 & 12.55 \\
\hline & 2 & 9.73 & 14.60 & 19.46 & 3.10 & 28.38 & 28.57 \\
\hline & 3 & 11.27 & 16.91 & 22.54 & 3.59 & 38.96 & 36.07 \\
\hline & 5 & 14.32 & 21.48 & 28.64 & 4.56 & 49.06 & 37.17 \\
\hline & 7 & 16.26 & 24.39 & 32.52 & 5.18 & 53.43 & 39.57 \\
\hline \multirow{5}{*}{ FA } & 1 & 3.99 & 5.99 & 7.98 & 1.27 & 9.81 & 21.67 \\
\hline & 2 & 8.51 & 12.77 & 17.02 & 2.71 & 27.55 & 29.02 \\
\hline & 3 & 10.02 & 15.03 & 20.04 & 3.19 & 31.50 & 33.11 \\
\hline & 5 & 11.68 & 17.52 & 23.36 & 3.72 & 42.67 & 37.10 \\
\hline & 7 & 12.24 & 18.36 & 24.48 & 3.90 & 51.91 & 40.09 \\
\hline \multirow{5}{*}{$\begin{array}{l}\text { Trinary } \\
\text { binder }\end{array}$} & 1 & 3.52 & 5.28 & 7.04 & 1.12 & 10.36 & 19.54 \\
\hline & 2 & 8.04 & 12.06 & 16.08 & 2.56 & 23.48 & 27.94 \\
\hline & 3 & 11.62 & 17.43 & 23.24 & 3.70 & 30.77 & 31.78 \\
\hline & 5 & 12.62 & 18.93 & 25.24 & 4.02 & 46.20 & 36.50 \\
\hline & 7 & 16.04 & 24.06 & 32.08 & 5.11 & 52.88 & 39.30 \\
\hline
\end{tabular}

spring and the other was seated on the loading side (Figure 3). The load difference between two load sensors was within $\pm 0.01 \mathrm{kN}$. The strain of the tensile specimen was measured by electrical resistance strain gauge (whose accuracy is $1 \mu \varepsilon$ ). The autogenous shrinkage test method without load (Figure 4) was performed with the same method that was presented in Gu et al. [23] and Ni et al. [32]. The autogenous shrinkage deformation was measured by a high-precision displacement sensor (whose accuracy is $0.001 \mathrm{~mm}$ ). The experimental results of mechanical property related to tensile creep are shown in Table 4 .

\section{Results and Discussion}

3.1. Influence of Loading Age and Admixtures on Tensile Creep. Several literatures [3, 23-33] had shown that loading age had a very prominent impact on the early-age creep of concrete. Some research $[29,30]$ results showed that the tensile creep of high-strength concrete containing admixtures was also strongly influenced by the loading age.

Figures 5 and 6 show the tensile specific creep of HSC containing FA and BS at different loading ages, i.e., 1, 2, 3, 5, and $7 \mathrm{~d}$, under three different stress/strength ratios. It can be seen from the figures that the HSC containing FA or BS was characterized that they had greater creep capacity at the earlier loading age. Under three different stress/strength ratios, the influence of loading age on creep was decreased at $3 \mathrm{~d}$ age and later ages.
Figure 7 shows the tensile specific creep of HSC with trinary binder (cement, FA, and BS) depending on ages. The results showed that the influence of loading age on tensile creep of HSC containing trinary binder admixtures was similar to that containing FA or BS. Moreover, the effect of trinary binder admixtures on tensile specific creep gradually decreases with loading at later ages. However, the affected duration of trinary binder HSC tensile specific creep by loading age was longer compared with that containing single FA or BS, and there were differences between the creep curves after $3 \mathrm{~d}$ ages.

The effects of loading age on tensile creep of HSC without admixture at loading ages of $3 \mathrm{~d}$ and after $3 \mathrm{~d}$ were minimal, and the influence of loading age was only reflected in the very early age, viz. before $3 \mathrm{~d}$ age $[1,3]$. But this was not the case for HSC containing admixtures. This difference was due to that the hydration degree of HSC containing admixtures was relatively lower at the early age, the moving gel water was more, and the elastic modulus was lower. These phenomena would be conducive to the development of the creep, and the creep deformation was larger at the early ages. As the concrete age goes on, the hydration reaction continues to proceed, and the concrete microstructure tends to be dense and the internal removable gel water of concrete was reduced, so the capacity of tensile creep growth could also be decreased. Hence, the influence of loading age on tensile creep would be less significant at later ages. Obviously, the influences of the type, the quantity of admixtures, 

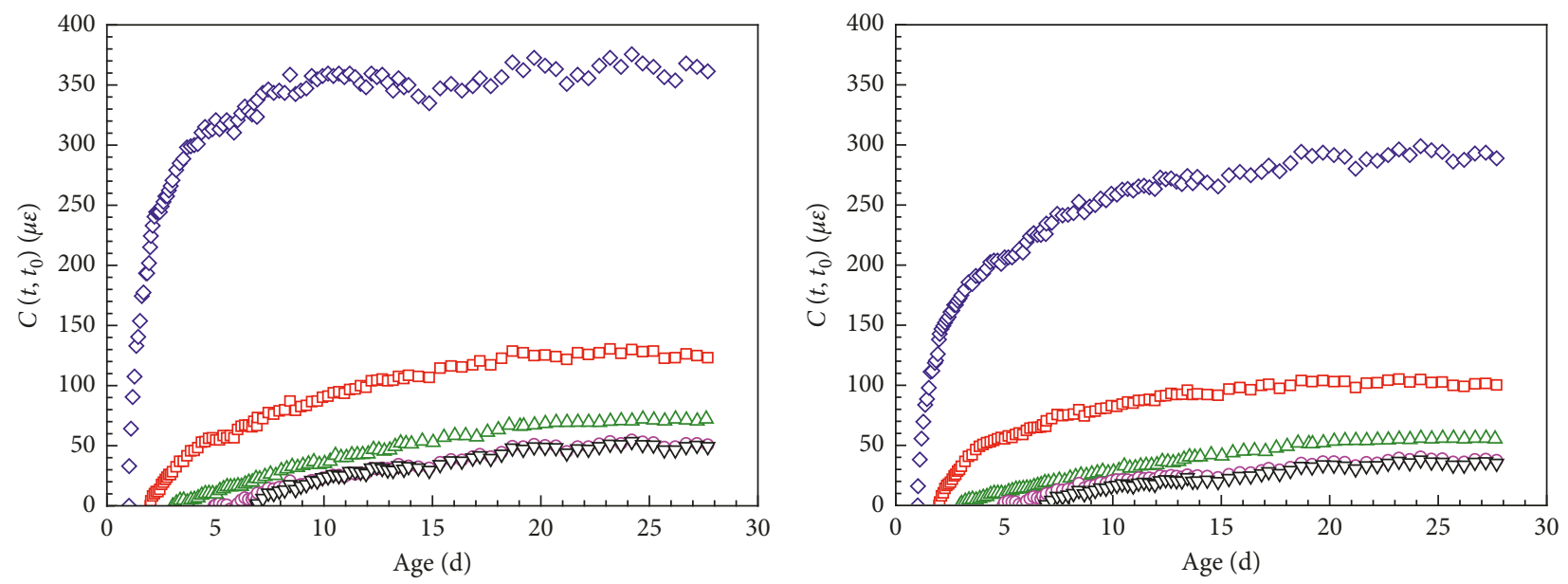

Loading age

$\begin{array}{ll}\diamond 1 \mathrm{~d} & \circ 5 \mathrm{~d} \\ \square 2 \mathrm{~d} & \nabla 7 \mathrm{~d}\end{array}$

Loading age

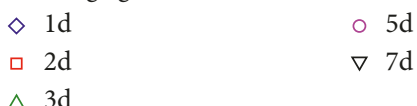

(a)

(b)

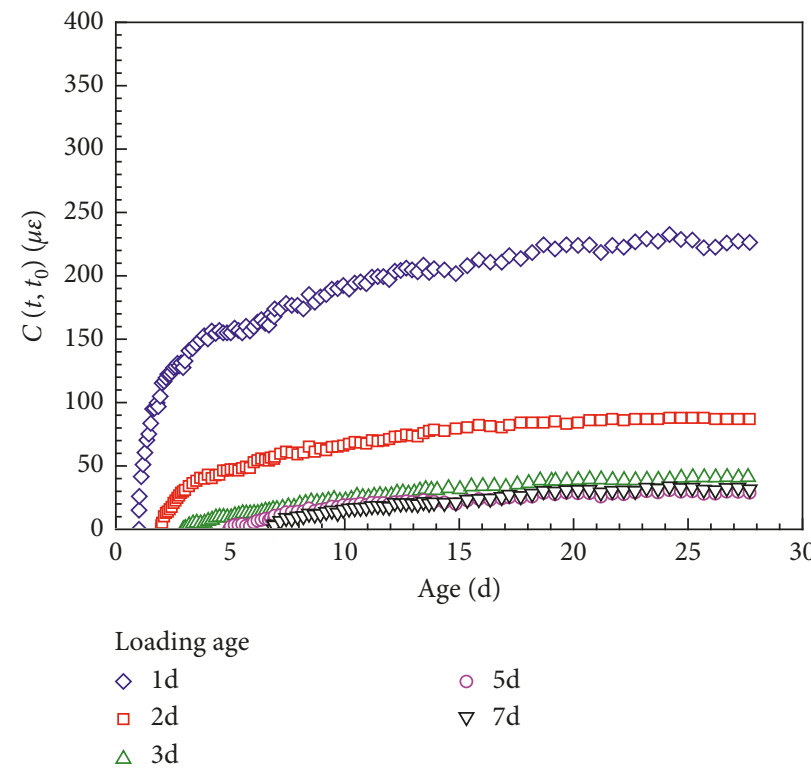

(c)

Figure 5: Specific creep of FA group at different loading ages. Stress/strength ratios: (a) 0.2, (b) 0.3, and (c) 0.4 .

and their combinations on hydration reaction of cementing materials were different, so the differences in the influences of loading ages on tensile creep of HSC containing different admixtures were exhibited.

By comparing the results of Figures 5-7, the results were also showed that the tensile creep value of the FA group was highest under different stress/strength ratios. Correspondingly, the BS group exhibited the lowest tensile creep. This difference was more significant at the loading age of $1 \mathrm{~d}$. It is shown in the table that FA has a larger average grain size than that of BS and cement, and its' activity and specific surface area are relatively low. Therefore, HSC containing FA showed lower strength at the same age. However, fly ash could restrain early autogenous shrinkage by changing the parameter of binder, such as hydrated velocity, creep coefficient, elastic modulus, and so on [34], and HSC with FA was exhibited to benefit the development of tensile creep. With the delay of loading age, the trend was obvious that the tensile creep value differences between the three groups were decreasing. So, the HSC containing admixture of FA can improve cracking resistance at early ages. Also, it can be explained that the larger tensile creep was more conducive to relieving the tensile stress.

3.2. Linear Feature of the Tensile Creep. By researching the effect of different loading ages on compression creep of mature concrete, Davis et al. [35] and Glanville [36] 


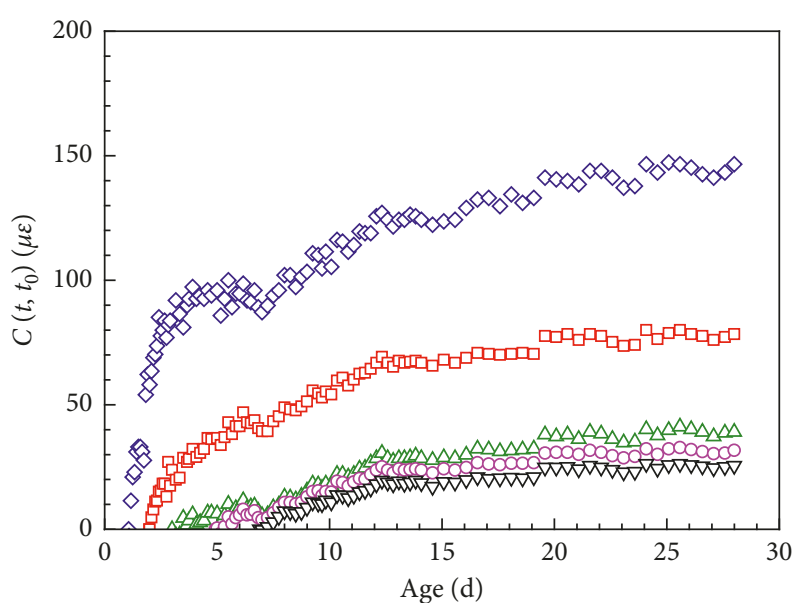

Loading age

$\begin{array}{ll}\diamond 1 \mathrm{~d} & \circ 5 \mathrm{~d} \\ \square 2 \mathrm{~d} & \nabla 7 \mathrm{~d}\end{array}$

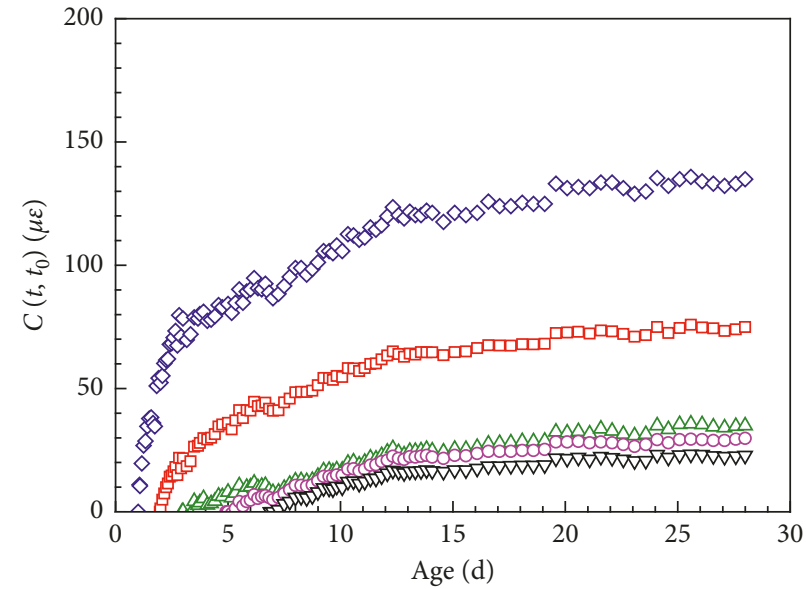

Loading age

$\begin{array}{ll}\diamond 1 \mathrm{~d} & \circ 5 \mathrm{~d} \\ \square 2 \mathrm{~d} & \nabla 7 \mathrm{~d} \\ \triangle 3 \mathrm{~d} & \end{array}$

(b)

(a)

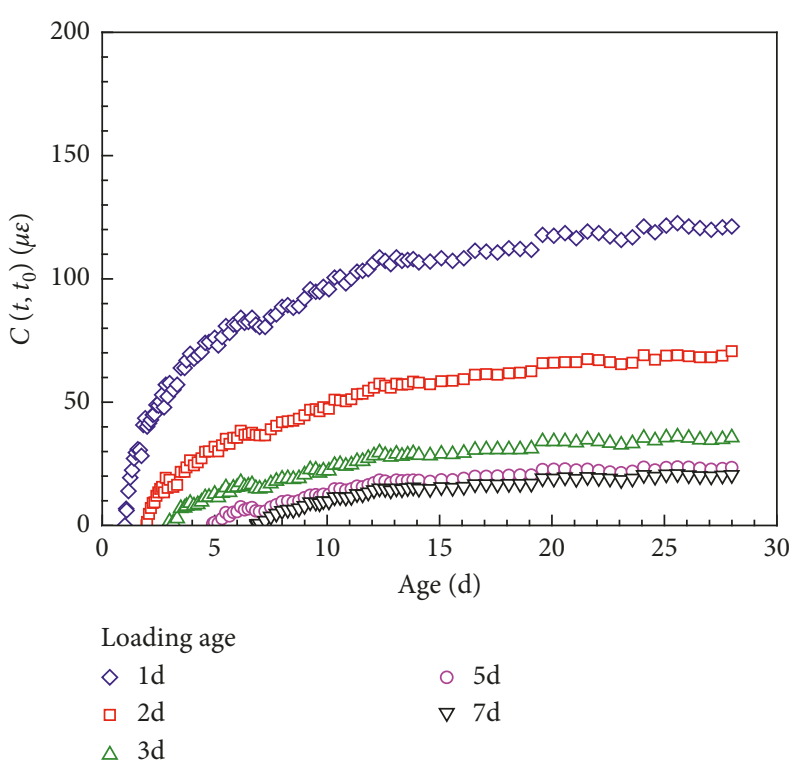

(c)

Figure 6: Specific creep of BS group at different loading ages. Stress/strength ratios: (a) 0.2 , (b) 0.3, and (c) 0.4.

discovered a linear relationship between creep and stress when the stress/strength ratio was less than 0.4, and the creep curve was independent of loading age; i.e., concrete specific creep curves should coincide at the arbitrary loading age. Neville et al. [1] called it as the "Davis-Glanvile" rule. Atrushi [4] found that the tensile creep of concrete also had a linear characteristic when the stress level was below 0.6. Similar results were obtained by Yang et al. [3, 27, 28, 37] on HSC without admixture. The results of Yang et al. showed that the tensile creep of HSC had obvious linear characteristics under the stress/strength range of 0.4 when the loading age was later than $1 \mathrm{~d}$.

The relative specific creep (tensile creep under the stress/ strength ratio of 0.2 or 0.4 /tensile creep under the stress/ strength ratio of 0.3 ) after $14 \mathrm{~d}$ or $28 \mathrm{~d}$ loading was calculated and is presented in Figure 8. In theory, while the relative specific creep equals to 1 , viz. the tensile specific creep values were equal under different stress/strength ratios, concrete tensile creep exhibited a linear characteristic at that time. Considering the influence of experimental conditions and measurement scatters, the value range of relative specific creep of $1 \pm 0.1$ was considered in the scope of the linear creep. Figure 8 shows that the tensile creep of HSC containing admixtures at early age does not all accord with the "Davis-Glanvile" linear rule at all the loading ages. Figure 8(a) shows the relative tensile creep of the FA group at $5 \mathrm{~d}$ loading age and loading $14 \mathrm{~d}, 28 \mathrm{~d}$ under the stress/ strength ratio of $0.2,0.4$. The results showed that the relative 

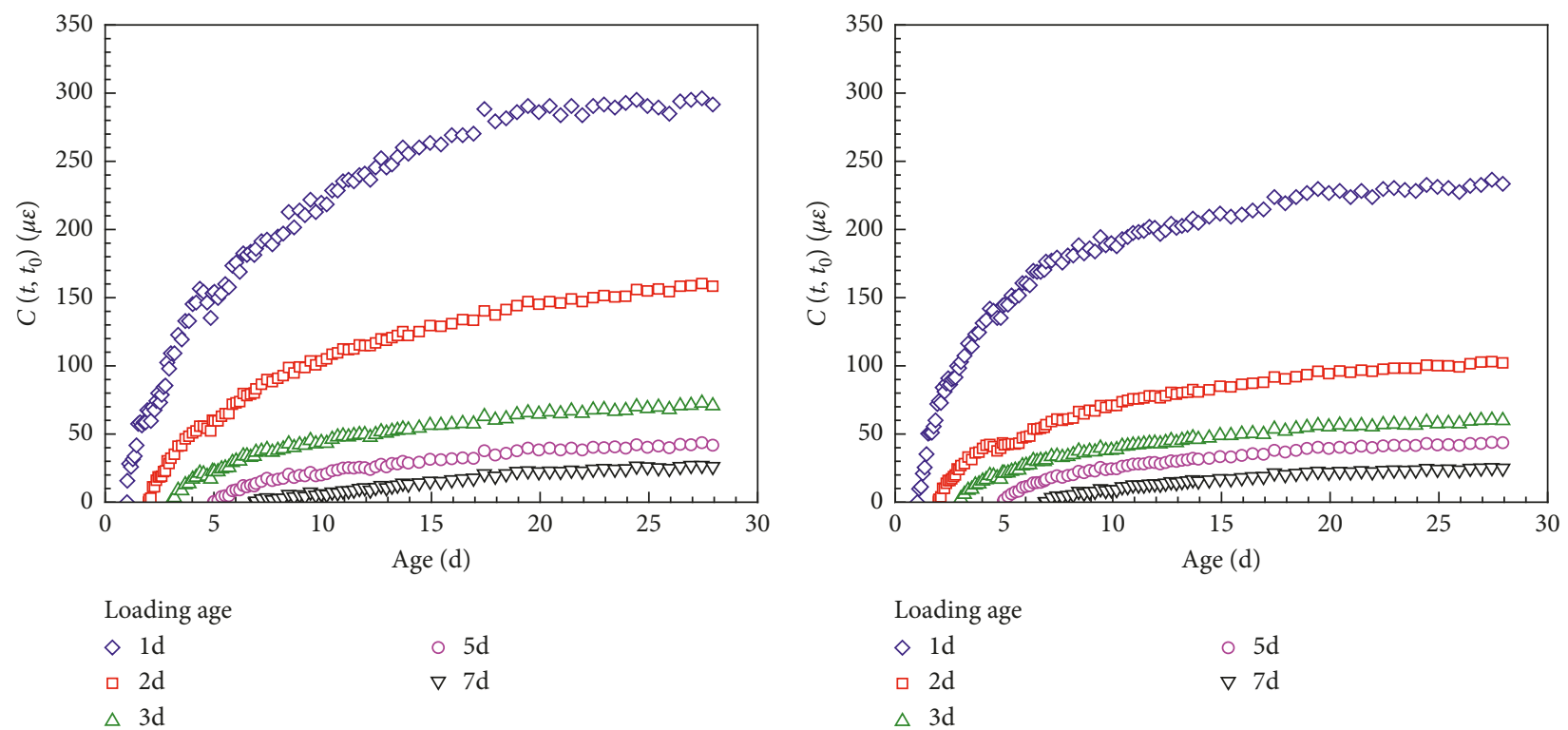

(a)

(b)

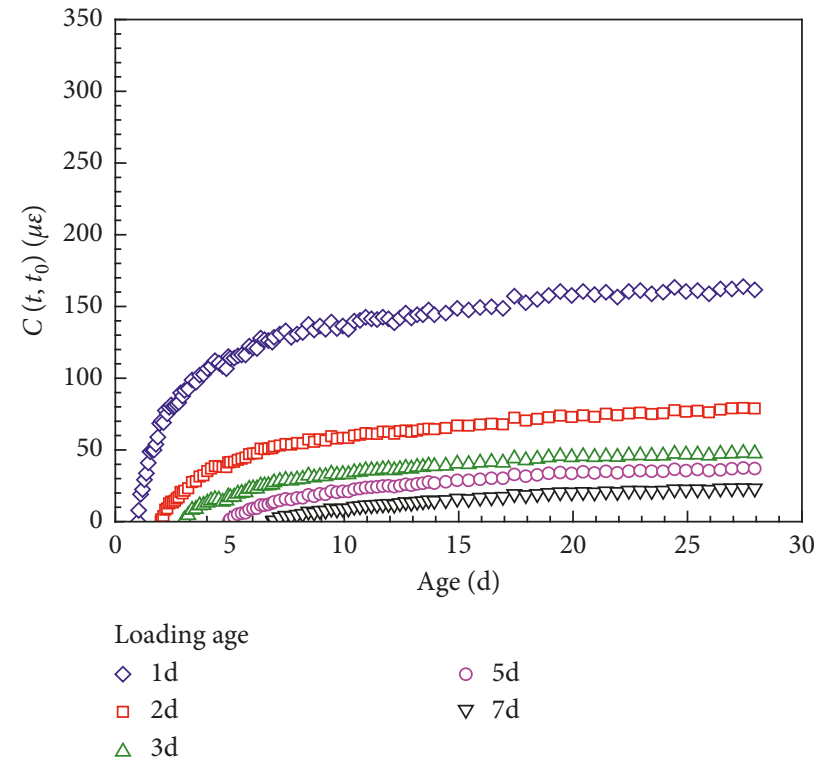

(c)

FiguRE 7: Specific creep of trinary binder group at different loading ages. Stress/strength ratios: (a) 0.2 , (b) 0.3 , and (c) 0.4 .

tensile creep values run into the $1 \pm 0.1$ range dotted edge, when the loading age getting later. It was considered that concrete presented the trend of creep curve coincidence, viz. the trend of linear creep, or the linear creep characteristic trend. While at $7 \mathrm{~d}$ loading age, the relative tensile creep values completely run into the dotted line, being showed good linear creep characteristics. But the BS group's relative tensile creep values (Figure $8(\mathrm{~b})$ ) at $2 \mathrm{~d}$ loading age have run into the dotted line, being showed the good linear creep characteristics. The data of Figure 8(c) showed that the trinary binder group's relative tensile creep at $5 \mathrm{~d}$ loading age and loading $14 \mathrm{~d}$ run into the dotted area, exhibiting the linear creep characteristics. The experimental results showed that the linear creep characteristic of BS appears the earliest, then the trinary binder group, and the FA group was the latest. Similar to HSC without admixture [3,37], the tensile creep of HSC containing admixtures at early age also showed linear creep characteristics after a certain loading age. But the duration of nonlinear creep characteristic was longer when admixtures were presented, and the linear feature would be exhibited more obviously while the loading age was later.

3.3. Tensile Creep Rate. In order to investigate the development of early-age tensile creep, load duration of the tensile creep was divided into three age periods: initial holding loading stage (initial holding loading to $3 \mathrm{~d}$, i.e., $0-3 \mathrm{~d}$ ), 


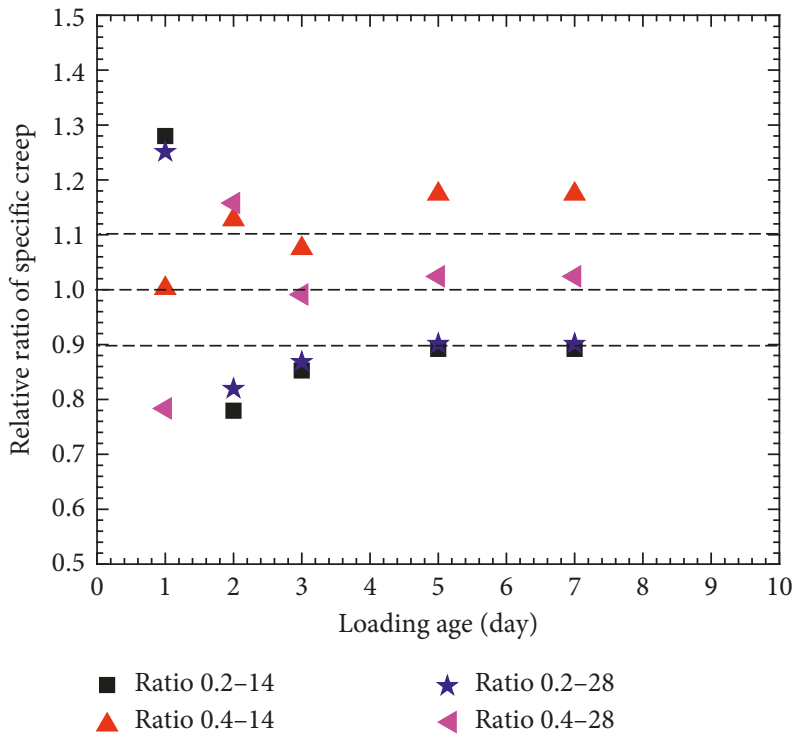

(a)

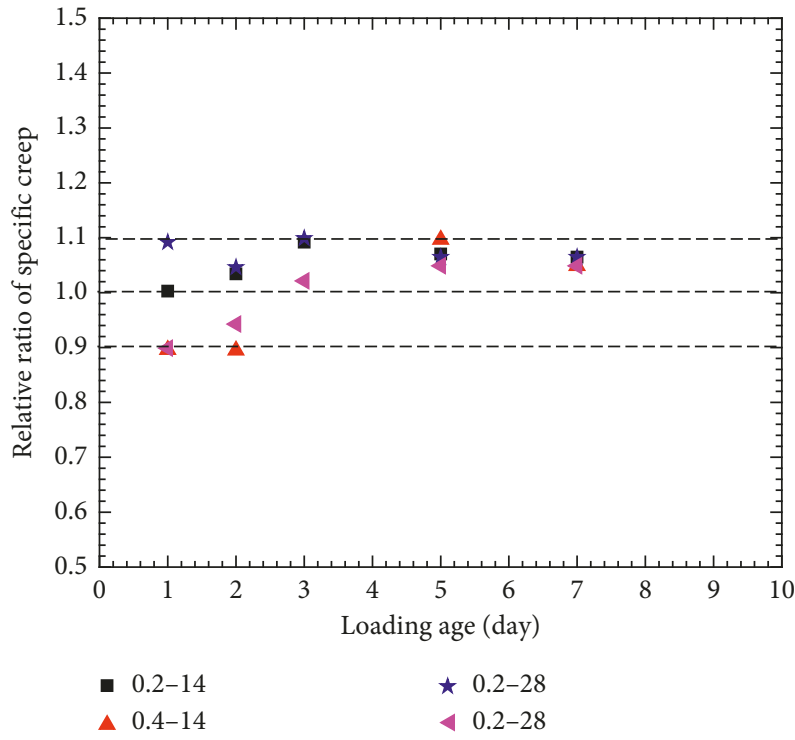

(b)

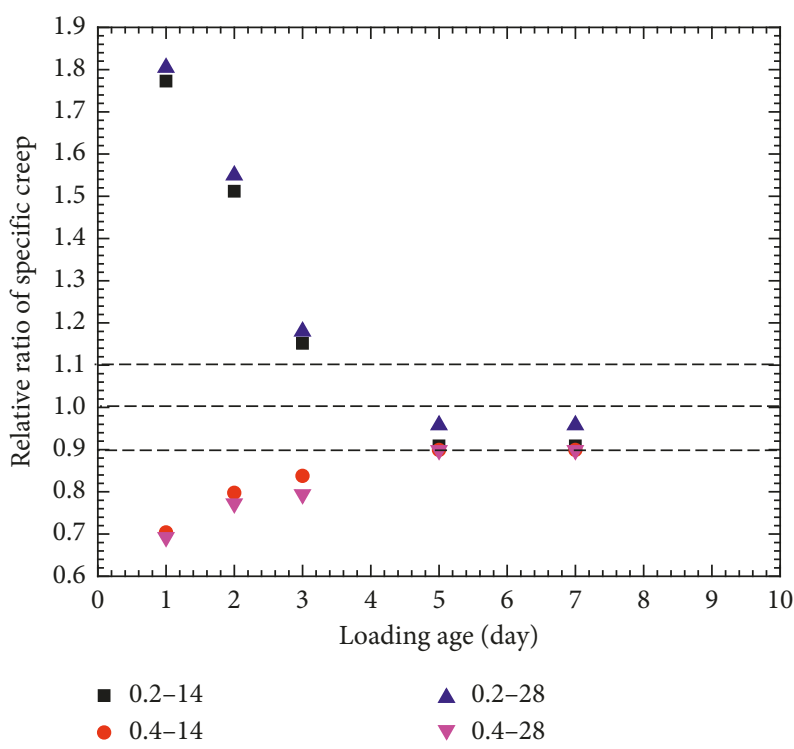

(c)

FIGURE 8: Relative specific creep (tensile creep under the stress/strength ratio of 0.2 or $0.4 /$ tensile creep under the stress/strength ratio of 0.3 ): (a) FA, (b) BS, and (c) trinary binder.

middle holding loading stage $(3 \mathrm{~d}-7 \mathrm{~d})$, and late holding loading stage ( $7 \mathrm{~d}$ to unloaded). The tensile creep velocities of these three stages were calculated in order to study the influence of admixtures on tensile creep development speed at early ages.

Figure 9(a) shows that the tensile creep velocity values of all mixtures were larger while loading age was earlier at $3 \mathrm{~d}$ loading age or before, and the tensile creep velocities became stable after $3 \mathrm{~d}$ loading age. That was to say, the effects of admixtures on tensile creep velocities were more significant while the loading age was earlier. The data of Figure 9 also showed that the tensile creep velocity of the FA group was largest, and the trinary binder group followed, and that of the BS group was smallest. The effects of admixtures on the tensile creep velocities were gradual attenuation as delay load duration. The creep development was similar to that of HSC without admixture at the early age $[25,26]$, and the tensile creep velocities also have a law of exponential decay.

\section{Conclusions}

The following conclusions can be obtained based on this study:

(i) The loading age significantly influences the tensile creep of HSC containing mixtures at the early age. The values of creep were higher while the loading age was earlier, and its influence on the tensile creep gradually decreased with the loading age getting 


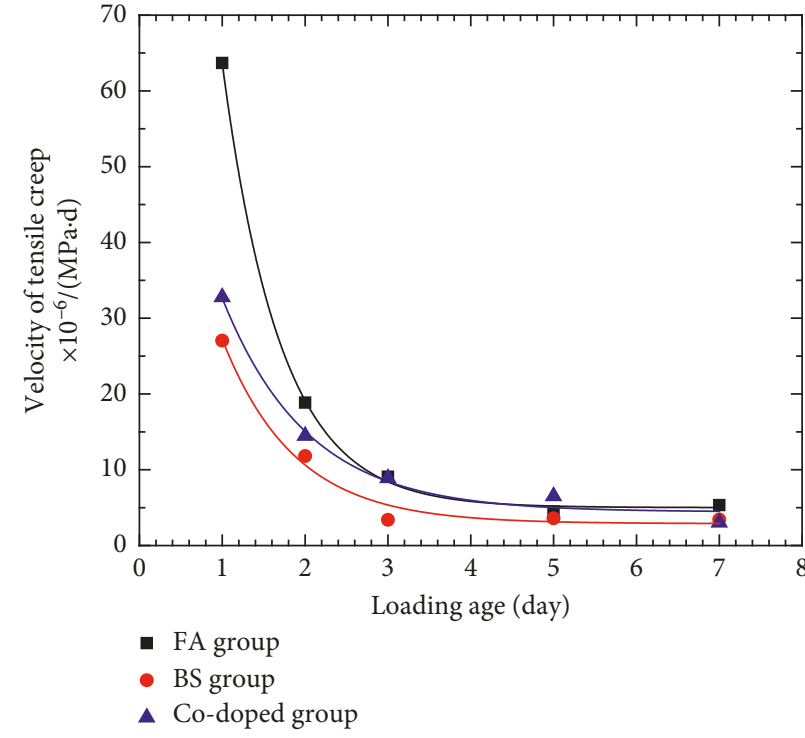

(a)

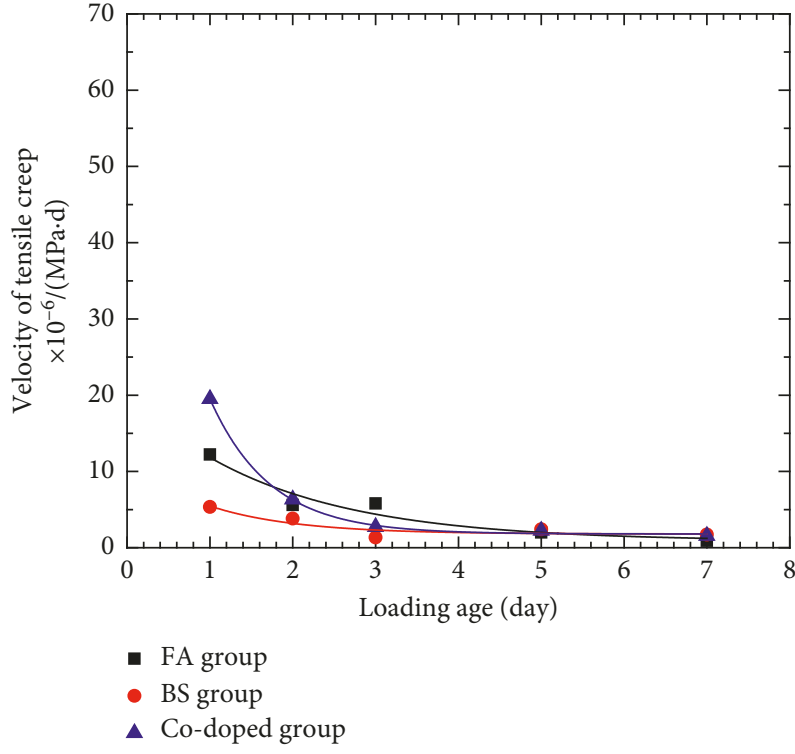

(b)

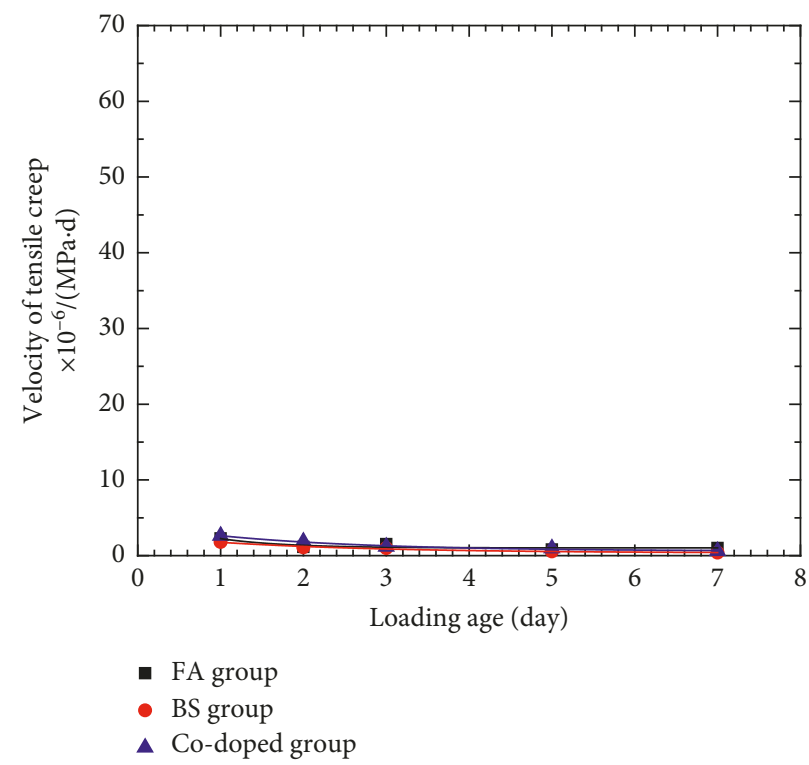

(c)

Figure 9: Tensile creep velocity of different loading durations (a) from $0 \mathrm{~d}$ to $3 \mathrm{~d}$, (b) from $3 \mathrm{~d}$ to $7 \mathrm{~d}$, and (c) from $7 \mathrm{~d}$ to unload age.

later. The affected ages' duration was longer than that of concrete without mixture.

(ii) The tensile creep of HSC containing mineral admixtures follows FA group $>$ trinary binder group $>$ BS group. The difference was more pronounced when the loading age was earlier, and this difference was largely reduced when the loading age getting later.

(iii) The early-age tensile creep of HSC with admixtures showed a linear creep characteristic after a certain concrete age similar to that of without admixture, but this age was delayed. The BS group was roughly $2 \mathrm{~d}$, while the FA and trinary binder group were $5 \mathrm{~d}$ age. The linear characteristics would be more significant while the loading age was late.

(iv) The tensile creep velocity of the FA group was larger than the other two groups, and followed by the trinary binder group, and that of the BS group was the smallest. The effect of admixture on the tensile creep velocity was gradually attenuated with the age growth in the holding period.

\section{Data Availability}

The datasets in Chinese references generated and/or analysed during the current study are available in the CNKI repository at http://www.cnki.net/. The datasets in English 
references generated and/or analysed during the current study are available from the corresponding author or publisher upon reasonable request. All data generated or analysed during this study are included in this article (and its supplementary information files).

\section{Conflicts of Interest}

The authors declare that there are no conflicts of interest regarding the publication of this paper.

\section{Acknowledgments}

The authors gratefully acknowledge the financial support from the National Natural Science Foundation of China (Project nos. 51378471 and 51778583). They also thank everyone who provided assistance for this study. In addition, thanks are extended to everyone for their contributions to the experimental work.

\section{References}

[1] A. M. Neville, W. H. Dilger, and J. J. Brooks, Creep of Plain and Structural Concrete, Construction Press, Detroit, MI, USA, 1983.

[2] Z. P. Bažant, "Concrete fracture models: testing and practice," Engineering Fracture Mechanics, vol. 69, no. 2, pp. 165-205, 2002.

[3] Y. Yang, S. Xu, D. Ye et al., "Tensile creep behavior of high strength concrete at early ages," Journal of the Chinese Ceramic Society, vol. 37, no. 7, pp. 1124-1129, 2009, in Chinese.

[4] D. S. Atrushi, Tensile and compressive creep of early age concrete: testing and modelling, Ph.D. thesis, Norwegian University of Science and Technology, Trondheim, Norway, 2003.

[5] P. Rossi, J. P. Charron, M. Bastien-Masse, J.-L. Tailhan, F. Le Maou, and S. Ramanich, "Tensile basic creep versus compressive basic creep at early ages: comparison between normal strength concrete and a very high strength fibre reinforced concrete," Materials and Structures, vol. 47, no. 10, pp. 1773-1785, 2014.

[6] N. Ranaivomanana, S. Multon, and A. Turatsinze, "Tensile, compressive and flexural basic creep of concrete at different stress levels," Cement \& Concrete Research, vol. 52, no. 10, pp. 1-10, 2013.

[7] B. Bissonnette, M. Pigeon, and A. M. Vaysburd, "Tensile creep of concrete: study of its sensitivity to basic parameters," ACI Materials Journal, vol. 104, no. 4, pp. 360-368, 2007.

[8] P. Rossi, J.-L. Tailhan, F. Le Maou et al., "Basic creep behavior of concretes investigation of the physical mechanisms by using acoustic emission," Cement and Concrete Research, vol. 42, no. 1, pp. 61-73, 2012.

[9] Y. Gaillet, W. Guo, and S. Liang, "Microprestresssolidification theory-based tensile creep modelling of earlyage concrete: considering temperature and relative humidity effects," Construction and Building Materials, vol. 127, pp. 618-626, 2016.

[10] S. A. Altoubat and D. A. Lange, "Creep, shrinkage, and cracking of restrained concrete at early age," ACI Materials Journal, vol. 98, no. 4, pp. 323-331, 2001.

[11] Z. Tao and Q. Weizu, "Tensile creep due to restraining stresses in high-strength concrete at early ages," Cement and Concrete Research, vol. 36, no. 3, pp. 584-591, 2006.
[12] Y. Lee, S.-T. Yi, M.-S. Kim, and J.-K. Kim, "Evaluation of a basic creep model with respect to autogenous shrinkage," Cement and Concrete Research, vol. 36, no. 7, pp. 1268-1278, 2006.

[13] A. Kim, F. Benboudjema, A. Darquennes, Y. Berthaud, and G. Nahas, "Modeling basic creep in concrete at early-age under compressive and tensile loading," Nuclear Engineering and Design, vol. 269, pp. 222-230, 2014.

[14] Y. Berthaud, S. Liang, and W. Guo, "Decoupling of autogenous shrinkage and tensile creep strain in high strength concrete at early ages," Experimental Mechanics, vol. 57, no. 3, pp. 475-485, 2017.

[15] T. Ni, Y. Yang, D. Wu, and C. Jiang, "Influences of environmental conditions on the cracking tendency of dry-mixed plastering mortar," Advances in Materials Science and Engineering, vol. 2018, Article ID 9160801, 9 pages, 2018.

[16] S. E Wallah, "Creep behaviour of fly ash-based geopolymer concrete," Civil Engineering Dimension, vol. 12, no. 2, 2010.

[17] G. M. Ji, T. Kanstad, Ø. Bjøntegaard, and E. J. Sellevold, "Tensile and compressive creep deformations of hardening concrete containing mineral additives," Materials and Structures, vol. 46, no. 7, pp. 1167-1182, 2013.

[18] X. Wang and Q. Xia, "Experimental study on the influence of fly ash on the early-aged tensile creep and other properties of concrete," Journal of Changzhou University, vol. 27, 2015, in Chinese.

[19] K. Qin, Y. Duan, and L. Guo, "Study on the tensile creep model of the admixture of early-age concrete and application simulation," Open Civil Engineering Journal, vol. 9, no. 1, pp. 1002-1006, 2015.

[20] Z. He, C. Qian, L. Li, and S. Du, "Creep analysis of concrete with different mineral admixtures," Materials Express, vol. 6, no. 4, pp. 328-336, 2016.

[21] M. D. Du, S. A. Altoubat, and D. A. Lange, "Early age tensile creep and shrinkage of concrete with shrinkage reducing admixtures," in Creep, Shrinkage and Durability Mechanics of Concrete and other Quasi-Brittle Materials, Z. Bazant, F. Ulm, and F. H. Wittman, Eds., pp. 685-690, Boston, MA, USA, 2001.

[22] K. V. Subramaniam, R. Gromotka, S. P. Shah, K. Obla, and R. Hill, "Influence of ultrafine fly ash on the early age response and the shrinkage cracking potential of concrete," Journal of Materials in Civil Engineering, vol. 17, no. 1, pp. 45-53, 2005.

[23] C. Gu, Y. Wang, F. Gao et al., "Early age tensile creep of high performance concrete containing mineral admixtures: experiments and modeling," Construction and Building Materials, vol. 197, pp. 766-777, 2019.

[24] D. Ye, "Study on tensile creep of high performance concrete at early ages," Master's thesis, College of Civil Engineering \& Architecture, Zhejiang University of Technology, Hangzhou, China, 2008, in Chinese.

[25] P. J. M. Monteiro and P. K. Mehta, Concrete: Structure, Properties and Materials, Prentice Hall, New York, USA, 1986.

[26] Z. P. BažAnt and S. Prasannan, "Solidification theory for concrete creep. I: formulation," Journal of Engineering Mechanics, vol. 115, no. 8, pp. 1691-1703, 1989.

[27] Y. Yang, C. Jiang, D. Ye et al., "Tensile creep prediction of HSC at early ages," Journal of Wuhan University of Technology, vol. 31, no. 7, pp. 77-80, 2009, in Chinese.

[28] Y. Yang, X. Lou, T. Ni, and Z. Wang, "Experimental study on the early-age tensile creep of high strength concrete containing blast furnace slag," Journal of Zhejiang University and Technology, vol. 45, no. 6, pp. 677-681, 2017, in Chinese. 
[29] Y. Yang, Y. Wu, P. Li et al., "Influence of loading age and curing temperature on tensile creep of HSC at early ages," China Concrete and Cement Products, vol. 174, no. 4, pp. 10-14, 2010, in Chinese.

[30] Y. Yang, Y. Wu, Z. Zhu, and S. Xu, "Evaluation of tensile creep of HPC at early ages based on equivalent age and internal structure," Journal of Southeast University (Natural Science Edition), vol. 40, no. 2, pp. 165-171, 2010, in Chinese.

[31] J. Chen, "Experimental study on the tensile creep at early ages of high strength concrete containing mineral admixture," Master's thesis, Zhejiang University of Technology, Hangzhou, China, 2017, in Chinese.

[32] T. Ni, Y. Yang, Y. Wu et al., "Experimental study on early-age tensile creep of high strength concrete under different curing temperatures," Journal of Building Materials, vol. 21, no. 5, pp. 732-738, 2018.

[33] D. Liu, "Influence of fly ash on early-age mechanical properties and tensile creep of high performance concrete," Master's thesis, Zhejiang University of Technology, Hangzhou, China, 2016, in Chinese.

[34] M. An, J. Zhu, W. Qin et al., "Study on fly ash restraints on the early shrinkage of high performance concrete and its mechanism," China Railway Science, vol. 27, no. 4, pp. P27P31, 2006, in Chinese.

[35] R. E. Davis, H. E. Davis, and J. S. Hamilton, Plastic Flow of Concrete under Sustained Stress, Vol. 34, Proceedings of ASTM International, West Conshohocken, PA, USA, 1934.

[36] W. H. Glanville, "Creep of concrete under load," The Structure Engineer, vol. 11, no. 2, pp. 54-57, 1933.

[37] D. Ye, Y. Yang, Z. Hong et al., "An experimental study on tensile creep of high performance concrete at early ages," Journal of Zhejiang University of Technology, vol. 36, no. 3, pp. 285-289, 2008, in Chinese. 


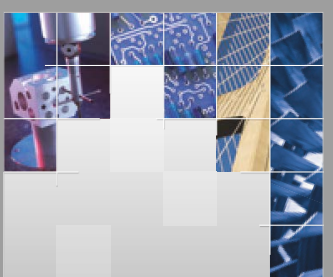

\section{Enfincering}
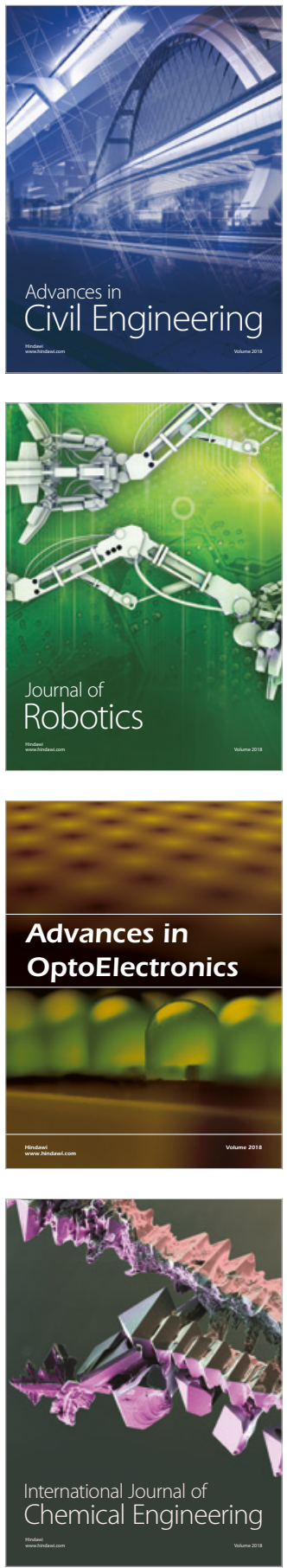

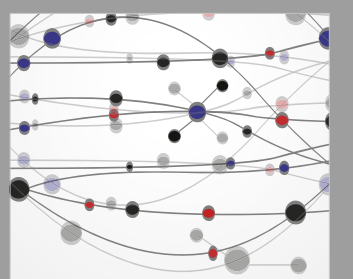

\section{Rotating \\ Machinery}

The Scientific World Journal

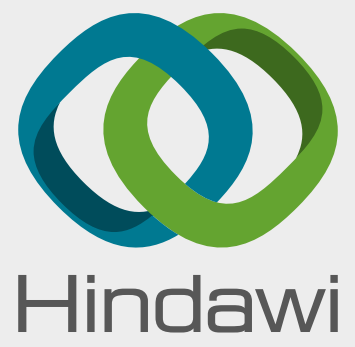

Submit your manuscripts at

www.hindawi.com
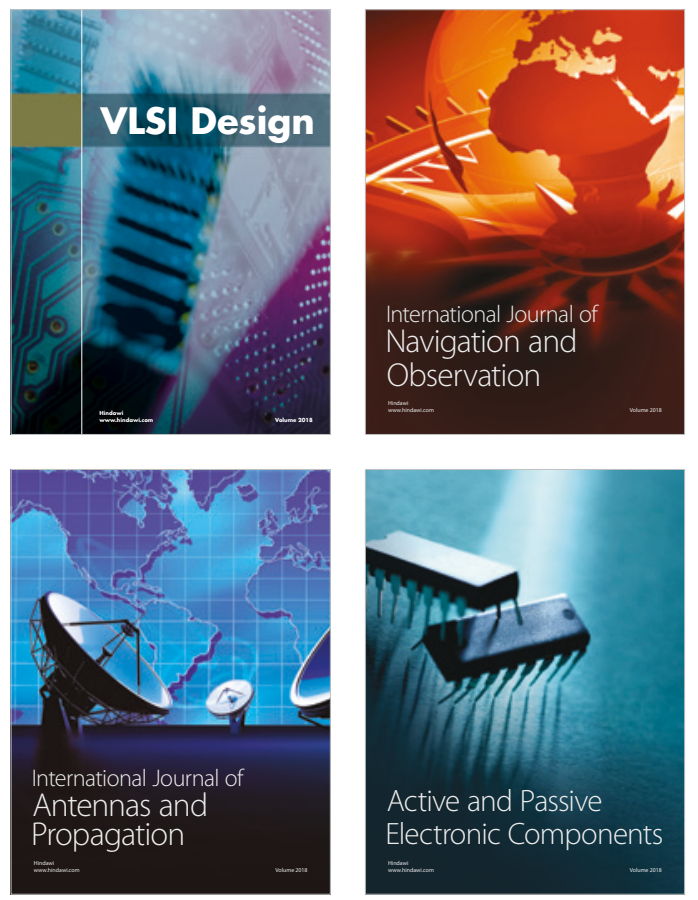
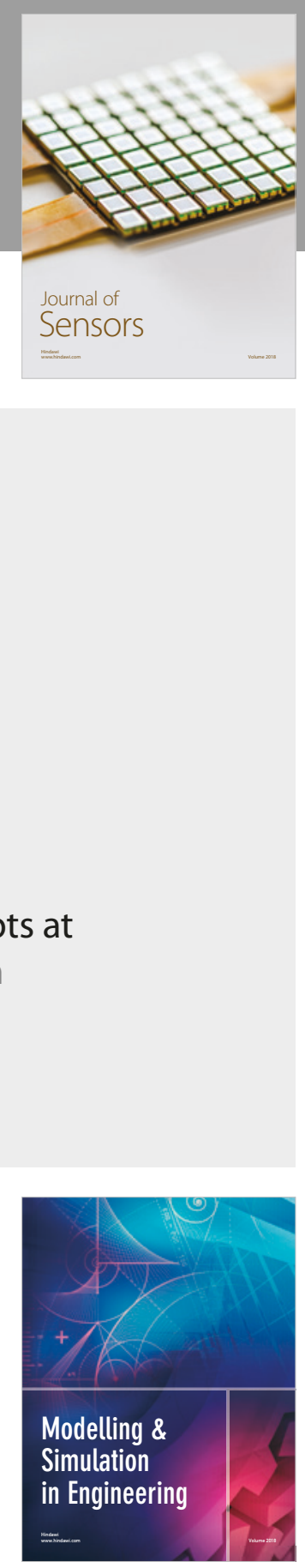

\section{Advances \\ Multimedia}
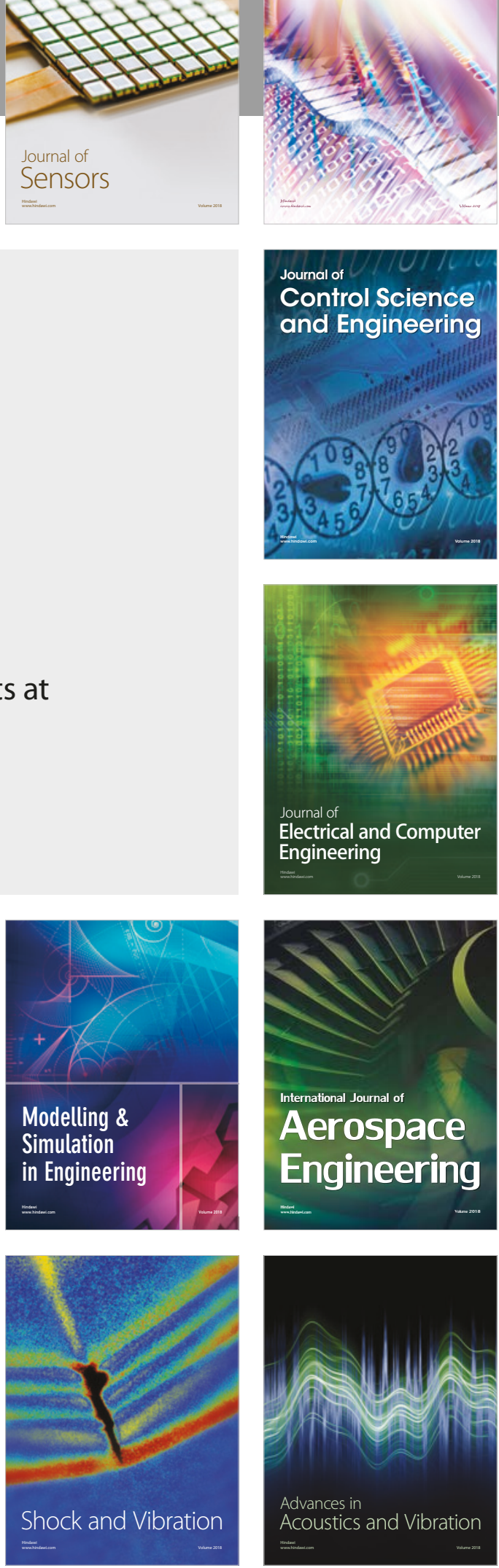